\title{
Public Plazas Physical Environment Affect People's Activities in the Cases of China and the USA
}

\author{
Maozhu Mao, Isami Kinoshita \\ Graduate School of Horticulture, \\ Chiba University, Japan \\ maomaofreedom@gmail.com, isamikinoshita@faculty.chiba-u.jp
}

\begin{abstract}
This study targeted on public plazas in Chongqing China and the Boston United States, and analyses several sites in neighborhood scale and spatial scale. Through field observations supported by William $\mathrm{H}$. Whyte's analysis, data were collected concerning people's activities in public plazas, and a discussion of how spatial factors have an effect on people's activities was down. The results suggest that Whyte's 7 components partly applied to China, and people's activities are vastly affected by spatial factors, and conjointly influenced by cultural background. Several elements work along may strengthen a vicinity way more.
\end{abstract}

Keywords: Public Plaza; Environmental Behavior; China; United States

eISSN 2398-4295 @ 2019. The Authors. Published for AMER ABRA cE-Bs by e-International Publishing House, Ltd., UK. This is an open-access article under the CC BY-NC-ND license (http://creativecommons.org/licenses/bync-nd/4.0/). Peer-review under responsibility of AMER (Association of Malaysian Environment-Behaviour Researchers), ABRA (Association of Behavioural Researchers on Asians) and CE-Bs (Centre for EnvironmentBehaviour Studies), Faculty of Architecture, Planning \& Surveying, Universiti Teknologi MARA, Malaysia.

http://dx.doi.org/10.21834/ajbes.v4i15.171 


\subsection{Introduction}

Within a century, the world's population has grown at an incredible speed, and over $1 / 2$ that population lives in cities. The fast rise in urban populations in developing countries brings with it several issues and challenges like pollutions and lack of space (Gehl, 2013). The general public plazas in developing countries, particularly, have a lot of issues like the very fact that areas are designed to be looked at, dysfunctional options and lots of others make plazas fail (Whyte, 1980).

China has experienced fast development throughout the last several decades, and also the development of modern culture has greatly influenced Chinese urban area over 30 years since 1979 beginning of the Chinese reform (Gaubatz, 2008). Whereas renewal in China has begun its fourth decade, the general public areas employed by normal residents haven't proportionately improved. There will be a lot of those who want public open area however the government developed 'Window-dressing' squares and parks, the monumental style push residents unwilling to use these forms of areas. The Chinese government and developers seldom think about people's participation, and that they understand very little regarding the residents' needs concerning open urban areas in the first place.

Researchers within the United States such as William H. Whyte conducted designoriented studies of human behavior in urban settings starting in 1969. Whyte spent sixteen years walking through the streets and public areas of New York City and observed the approach how individuals used space. He summarized seven key elements that are most significant to a town and town life: relationship to the street, seating, sun, water, trees, food, and triangulation (Whyte, 1980). He later started a research group and began the street Life Project explored his methodology of direct observation to research public spaces. Behavior mapping has proven a valuable tool in United States urban designing for creating informed decisions regarding the location and design of various facilities (Madden \& Wiley-Schwartz, 2010).

The urban open spaces in China and therefore the united states have several differences in culture, economy, population, social formations, etc. all these differences have impacts on the urban open area, however, planners design the place and the way individuals use the space. Moreover, each open public place is unique, they involve completely different cultures, interior structure, planting selection, weather conditions, a nearby street, and building activity, and with all these factors and plenty of others combined they create one single space. However, there's one issue that never changes-they all full of people. Of course, individuals could use the same spaces to conduct several activities, however, the sort of activities they participate in is almost the same. However these spaces are in different countries with different cultures, values, and views on life, the way in which people use public spaces have similarities.

Every open public place is unique, they involve different cultures, interior structure, planting choice, weather conditions, a nearby street, and building activity, and with all these factors and many others combined they make one single space. But there is one factor never changes-they all full of people. Of course, people may use the same spaces to take part in different activities, but the type of activities they participate in is almost the same. Even though spaces are in a different country with different cultures, values, and views on life, the 
way in which people make use of public spaces have similarities. So the intent of this study is to address the following questions:: (1) whether the William $\mathrm{H}$. Whyte's seven William elements also apply to China? (2) How urban public plazas used differently within the United States and China? The authors had chosen 2 cities for a case study, Chongqing in China and Boston in the United States. They analyzed these 2 cities in several different scales and conducted the observation.

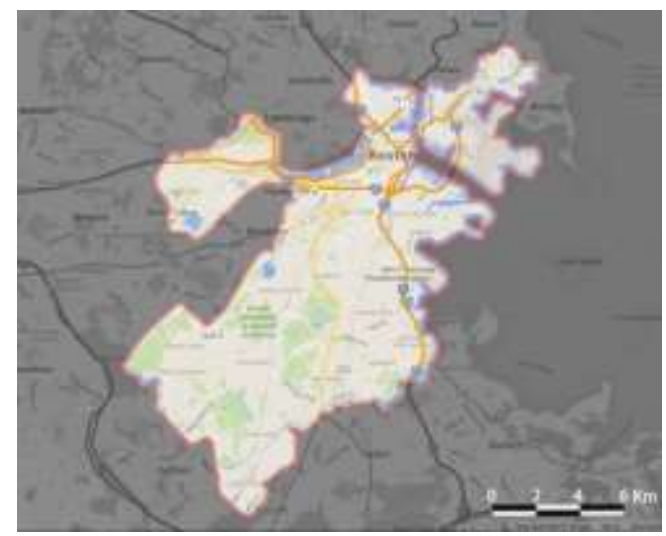

Figure 1: Main Boston Urban Area

(Source: modified based on Google Map)

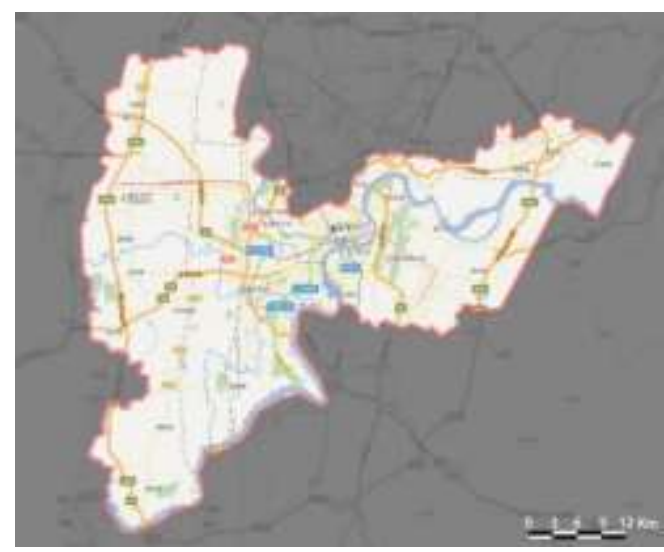

Figure 2: Main Chongqing Urban Area

(Source: modified based on Baidu Map)

\section{0 Literature Review}

The city is defined as a well-developed place where people work and live (Ramlee, Omar, Yunus, \& Samadi, 2015). Everything that can be part of the built environment in cities such 
as squares, streets, alleys, buildings, bollards are understood as public space (Gehl \& Savare, 2013). The creation of such parks has many benefits, both economic and civic. Public spaces like parks can raise the land values around the site, and some of the nearby houses have the highest sale prices. They also have lots of benefits for the environment, can add nice atmospheres for people and provide natural habitats for animals. "Those places people love to share some common characteristics, people feel safe, have fun, and feel welcome in those spaces. Successful spaces always share these qualities: accessibility, activities, comfort and sociability" (Madden \& Wiley-Schwartz 2010). Some public spaces fail for a variety of reasons. Many public spaces are designed to be looked at, but not for people to actually use like most plazas in front of Chinese local government buildings 20 years ago. Some other reasons include lack of gathering spots, poor entrances, and visually inaccessible space, dysfunctional features, paths that don't lead people where they want to go, domination of a space by vehicles, blank walls or zones around the edges of a space, or inactivity.

China changed a lot throughout the last decades, and therefore the economic process is changed so quickly that also vastly influenced the economy globally (Qiren, 2013). There are three types of problems with Chinese public open space proposed by Miao, window-dressing, privatization and gentrification. When the city gets a new mayor or governor, the city's urban projects can be changed to get big-budget developments and show the mayor's accomplishments. They hand over the development and management to private commercial developers, but the private entities always tend to maximize the short-term profits and damage the social life in adjacent public spaces. In those well-established commercial core area or urban centers, the developer and management prefer to serve privileged minorities such as the residents who have a higher income (Miao, 2011). With the economic development, the urban renovation in China also changed a lot, and therefore the development of the urban renovation is totally different comparing to the process in the West (Wu \& Gaubatz, 2013). The economic development also leads the urban revivification, and it's so vital that it influences economic, physical and social environment conjointly with historical and cultural of the urban area (Ramlee, Omar, Yunus, \& Samadi, 2015).

Public spaces such as plazas create vital value inside cities, people's needs from basic to complex are concerned within and have an effect on people's life quality (Jalaladdini \& Oktay, 2012). Plazas within the town with the completely different location, adjacent streets, and special styles might decide the number of people visit and also the activities they conduct within. Public plazas as a part of the green space within the city, the planning characteristics of natural and physical effect the social interaction level (Rasidi, Jamirsah, \& Said, 2012), that is a crucial need for people. Other needs such as safety also involved with vegetation in space that some vegetation might generate fear among people, too dense of vegetation, for example, might make people think about crime (Maruthaveeran, 2016). The surroundings considerably influence people, the interactions elements between nature and humans such as water and green space might enhance the interactions both human-nature and humanhuman (Omar, Ibrahim, \& Mohamad, 2017). Also, the spatial relationships within the urban space might be affected by both physical and behavioral, and people's behavior in a public space might be an objective reflection of the environment (Cheshmehzangi \& Heath, 2017). The relationships of physical environmental activities might offer very important data for 
planners and designers that may improve urban space design (Nasir, Ahmad, \& Ahmed, 2016). It is difficult that to have a top quality of design in each urban public space, and therefore the design factors might be the key to enhance the vitality and also the spatial experience (Wan \& Zhu, 2015).

William $\mathrm{H}$. Whyte as a pioneer researcher studied public space in New York City many years before and used direct observation technique in a systematic approach which is vital in assessing physical activities and distinctive activities. Whyte additionally proposed seven elements that required for good public spaces, and therefore the fowling are elements that he identified. 1) the relationship to the street: a good plaza starts at a street corner, therefore the relationship to the street will be one of the most vital aspects of space and the area wherever the street and plaza or open space meet could be a key to space's success. 2) Sitting space: people will sit nearly anywhere between a height of 1 foot $(30 \mathrm{~cm})$ to 3 feet $(90 \mathrm{~cm})$ as long as the seating is physically comfortable and socially comfortable is also needed. 3) Sun: it provides the warmth that in summer people typically sit in the sun as well as in the shade, however in cool weather, people will actively look for the sun. 4) Water: people prefer to have fun in and enjoy the water, it works as a sound buffer against other noise such as that from street traffic. 5) Trees: it helps people who beneath them feel comfortable and protected by the enclosure. 6) Food: it will attract people, which can attract a lot of people, it becomes a perfect place for social interaction. 7) According to Whyte's definition, triangulation could be a "stimulus" in addition as an interaction between people; they are conversation-starting things people prefer to talk about when they walk by. Some researchers additionally applied Whyte's technique in different countries and could get some agreement (Helden, 2015). Moreover, this study is also based on Whyte's research, analyses the study area in several scales and conduct observation in both China and the United States.

\subsection{Methodology}

To achieve the research objective, the methodology in this study has two main components, the analysis of the research sites and direct observation that relies on Whyte's study. The analysis part has two steps: 1) regional analysis 2) neighborhood analysis, 2) spatial analysis. These two steps of study start form city scale to spatial scale within the study sites. Through the analysis process, researchers may have both a general understanding of the research area and detail spatial information. Once after the analysis, researchers may conduct the observation systematically.

\subsection{Methodology Regional analysis}

The regional analyses analyzed two cities, one in the United States and one in China in several different ways. The regional analyses facilitate the process of target city collection that may share some similar properties. The two cities in this study are Boston, MA in the United States and Chongqing in China.

Boston is the capital and largest city of the Commonwealth of Massachusetts in the United States. It is one of the oldest cities within the United States, based on Shawmut peninsula in 1630 by Puritan settlers from England. When gaining independence from Great 
Britain, the town became a very important port and producing hub, furthermore as an academic and cultural center.

There are many faculties and universities within the city that create Boston a center of international higher education. The nation's oldest institution of higher education, Harvard, is located in Cambridge. With Massachusetts Institute of Technology, they have been ranked highest in the world. The city of the state capital is the economic and cultural center of the substantially larger metropolitan area known as greater Boston. The transportation system in Boston includes subway, roadway, regional rail, air, and sea options. Bus, subway, water ferries and short distance rail are operated by The Massachusetts Bay Transportation Authority (MBTA). Amtrak provides the rail service primarily from north-eastern cities. The South Station works as a major bus terminal served by several intercity bus corporations.

Chongqing is a major city in Southwest China, and one of the 5 national central cities in China is additionally one of China's four direct-controlled municipalities. The 2015 population of Chongqing was just over 30 million; this makes Chongqing the foremost populous Chinese municipality, and also the biggest direct-controlled municipality in China. There are 2 rivers within the city; the Yangtze River meets its major tributary stream, Jialing River in the central Chongqing, that the city is encircled by water and settled on a giant syncline valley. River ports in Chongqing work with numerous luxury cruise ships that end at Chongqing, cruising downstream on the Yangtze River to Yichang, Wuhan, Nanjing, and even Shanghai. Also, because of the construction of the Three Gorges Dam, the port has been improved access by giant cargo vessels that makes the transport of products along the Yangtze River possible. The general public transportation in Chongqing has 3 main forms; CRT metro, intercity railway, and the bus system.

\subsection{Neighbourhood analysis}

The research has 3 sites in each city. Neighborhood analysis is based on the sites in the city and analysis space around the sites. Every pair of sites may share a similar neighborhood around the space.

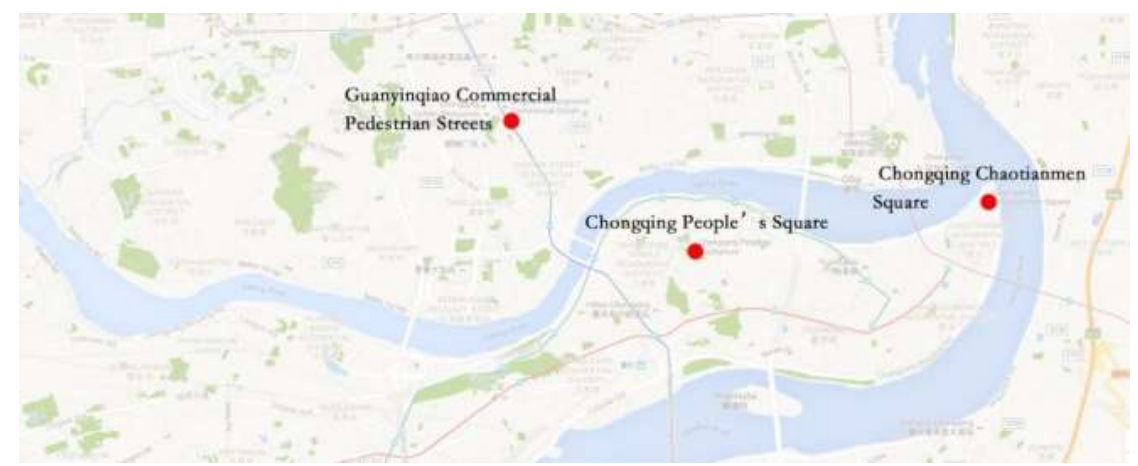

Figure 3: Three sites in Chongqing China

(Source: modified based on Google Map) 


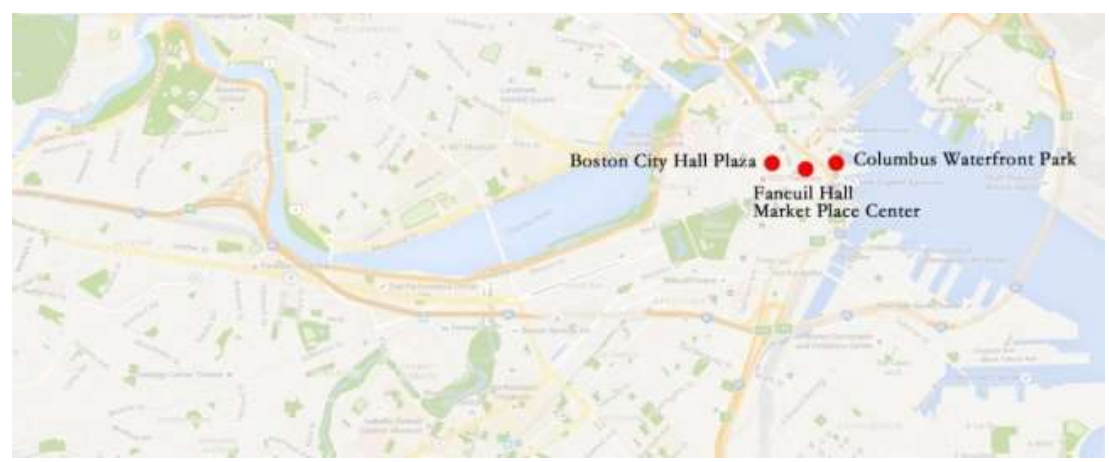

Figure 4: Three sites in Boston the USA

(Source: modified based on Google Map)

\subsubsection{Boston city hall Plaza}

Boston city hall Plaza is an unadorned Plaza in the Government Centre area of the city with Boston city hall behind it. The design of city hall, the spatial arrangement of the plaza and other structures around Government Centre was the responsibility of I.M.Pei (A ChineseAmerican architect), commissioned by Edward J. Logue. The City Hall and the Plaza were created between 1963 and 1968, and therefore the plaza consists of red brick and concrete with irregular shapes and multi-levels, which can make people consider it as a seedy space.

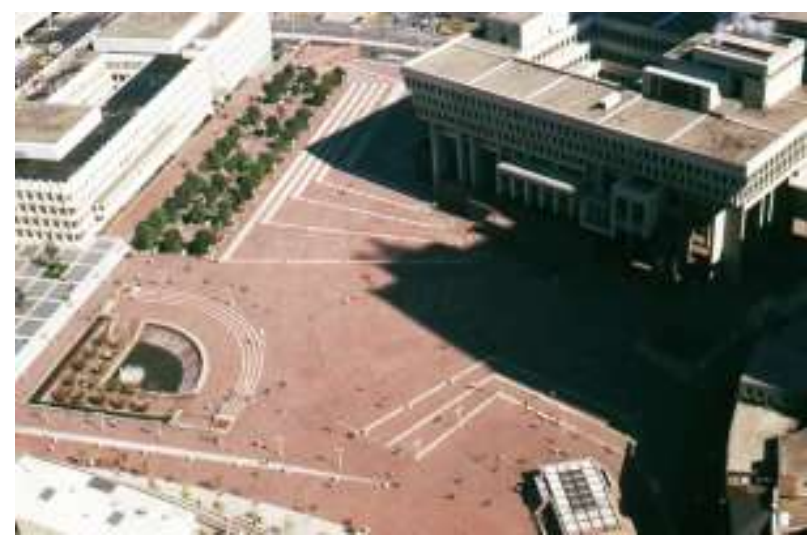

Figure 5: Boston City Hall Plaza

(Source: $h t$ tps://goo.gl/qHF3RQ)

Chongqing People's Auditorium, which can be translated as great hall of the people, is behind the Chongqing People's square and settled in central Chongqing. The great Hall of people was established in September 1951, completed in January 1954, and its exterior resembles the Temple of Heaven in Beijing. It was built in June 1997, the same time once Chongqing became a municipality directly below the central government. From then on the 
site became a public pace and the auditorium also holds public performance. Green surrounds the square, and thanks to Chongqing's mild climate, flowers bloom all years round. Nearly every evening, citizens will self-organize hundreds of people in the square to dance and do exercise.

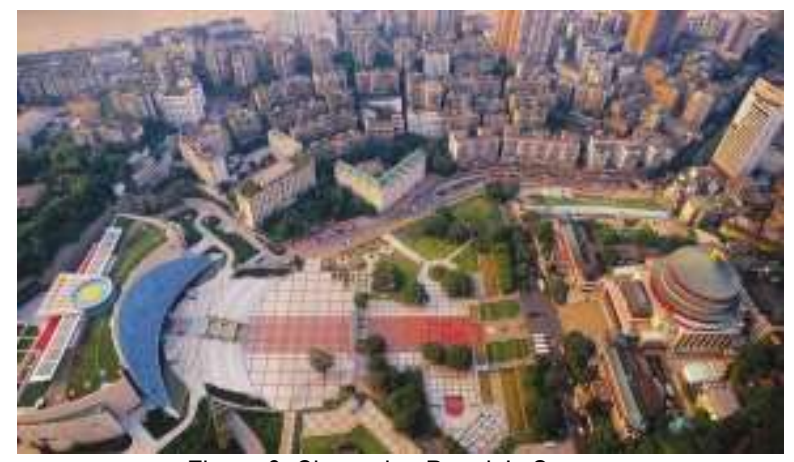

Figure 6: Chongqing People's Square (Source: $h$ ttp://goo.gl/9Hr1Ph)

\subsubsection{Boston Faneuil Hall Marketplace Centre and Guanyinqiao Commercial Pedestrian Streets}

The Faneuil Hall was built in September 1742 by artist John Smibert and is located in between today's Government Centre and the waterfront. It was worked as a marketplace and meeting hall since 1743. Currently, the place provides space for fast-food and food-stalls. Boston Faneuil Hall Marketplace is a popular place for workers in downtown to get lunch, with seating areas not only provided inside the building but also round the building in the form of stone benches, movable tables, and chairs

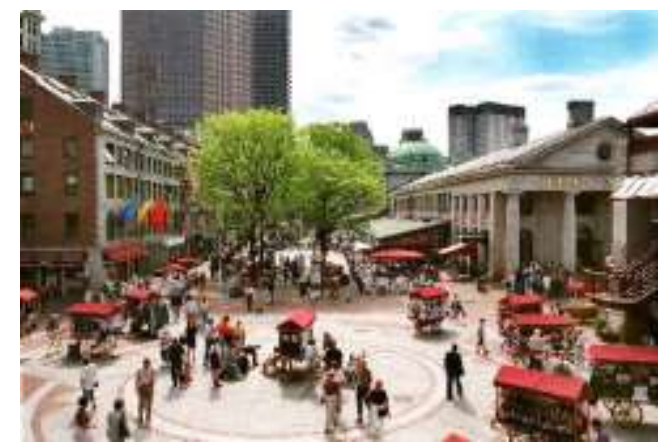

Figure 7: Boston Faneuil Hall Market Place Centre (Source: https://goo.gl/V9ePXx)

Guanyingqiao commercial Pedestrian Street is in Jiangbei district. Construction work was started in April 2003 by Longfor real estate. The business area consists of 3 parts: Jialing city 
Park, Guanyingqiao Plaza, and Guanyingqiao commercial Pedestrian Street. The resulting area is meant to combine natural beauty, tourism, shopping, and entertainment. The pedestrian street, together with food stores, provides seating space that allows around 2000 to people sit and enjoy their food.

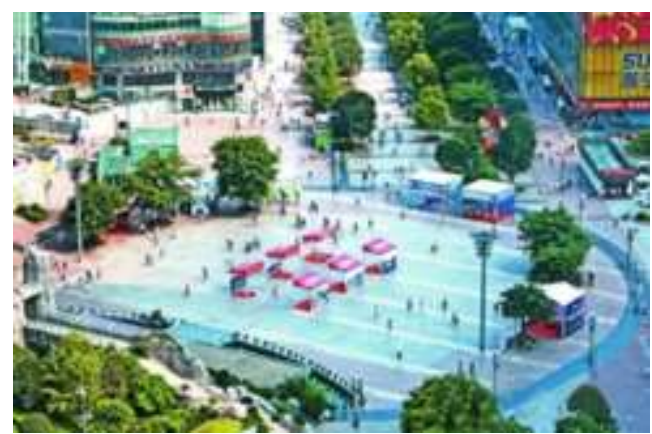

Figure 8: Chongqing Guanyinqiao Commercial Pedestrian Streets (Source: http://goo.gl/i9PIF2)

\subsubsection{Boston Columbus Waterfront Park and Chongqing Chaotianmen Square}

Columbus waterfront Park originally opened in 1976 and is a historic park that settled close to hall Plaza and linked to Faneuil Hall Marketplace. Sasaki did its original design and won many awards together with ASLA (American Society of Landscape Architects) Centennial Medallion Award in 1999. it is also one of American's earliest waterfront parks of the modern era. There is a pleasant playground for children within the park and the greenway simply across the street where kids could hop on the Carousel.

Chaotianmen square is in Yuzhong district, where Yangtze River meets its tributary Jialing River. Around 314 BC, Ba County's city gate was settled in Chaotianmen, which was later reworked into a wharf and extended in 1927. The Square, which was commissioned by Yazhi He, was made in 1998.

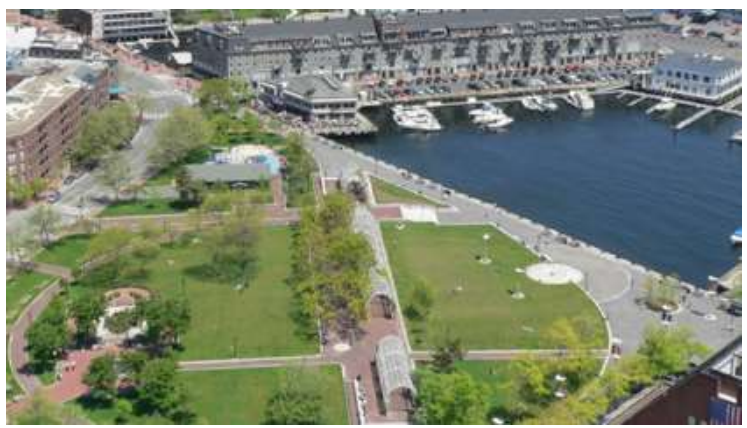

Figure 9: Boston Columbus Waterfront Park

(Source: http://goo.gl/okWTuZ) 


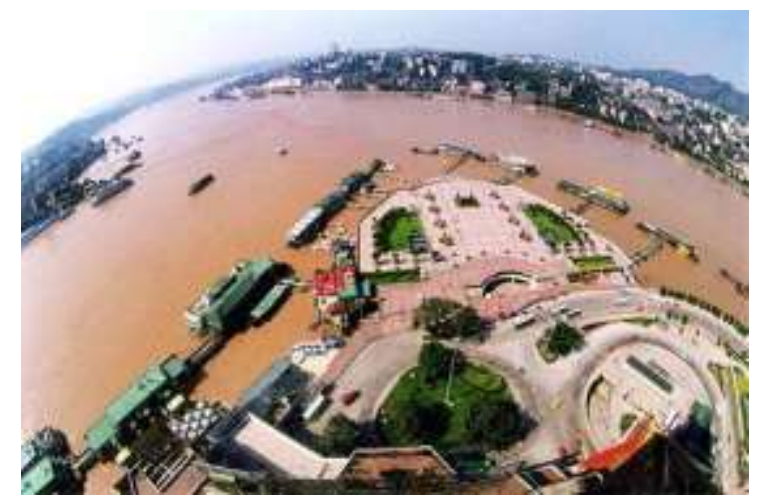

Figure 10: Chongqing Chaotianmen Square

\subsection{Spatial analysis}

(Source: $h$ ttp://goo.gl/d4WnaD)

The spatial analysis examines the details within the sites such as size, sitting space, food vendor, green area, and entrances. Analysis map created based on satellite pictures, and build the foundation for the on-site observation.

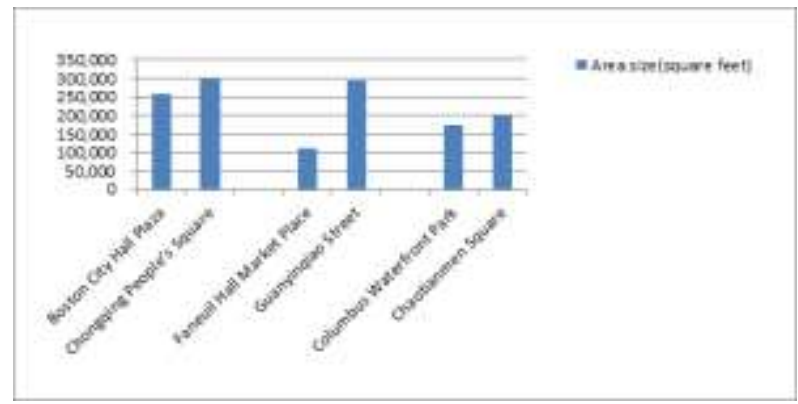

Figure 11: Area size of each pair of sites

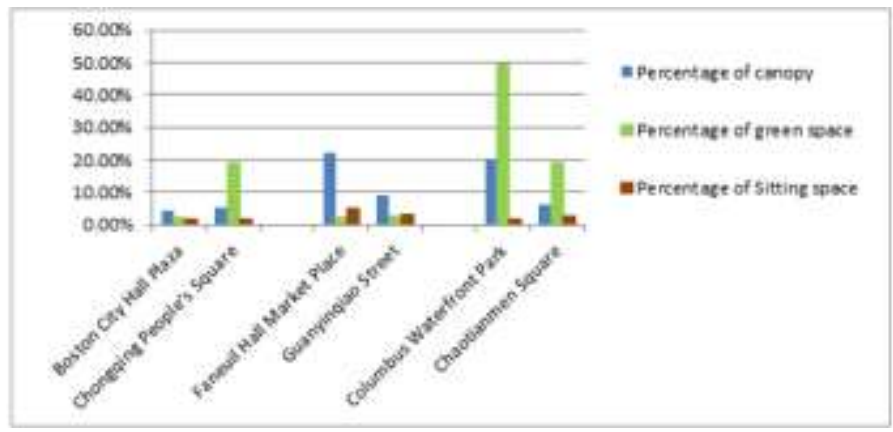

Figure 12: Percentage of the canopy, green space, and sitting space 


\subsubsection{Boston City Hall Plaza and Chongqing People's Square}

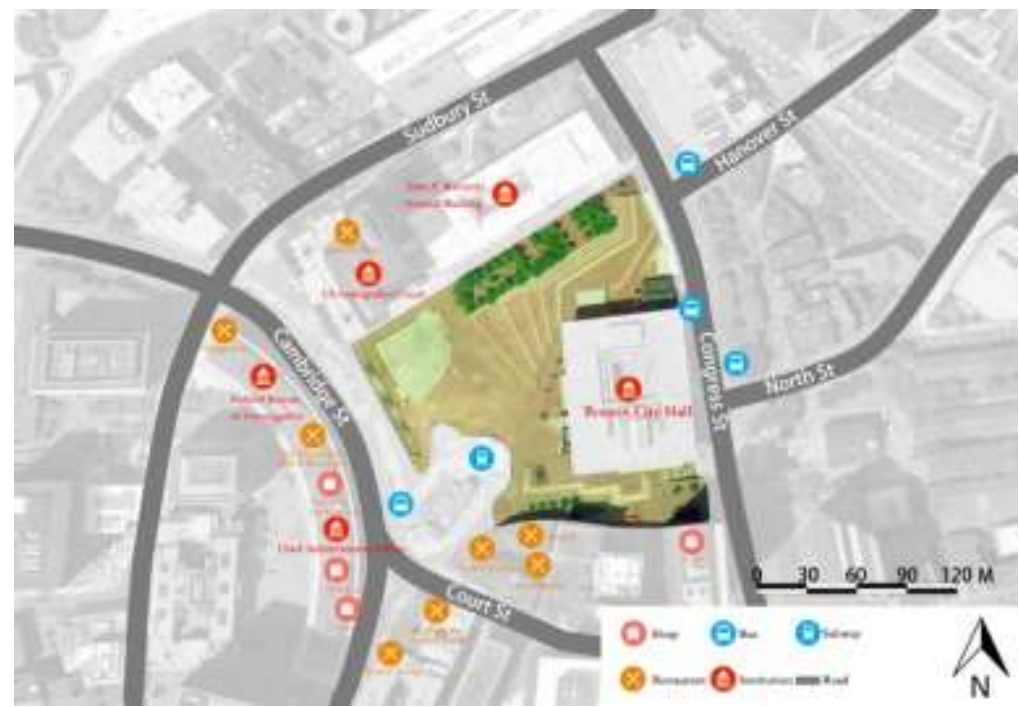

Figure 13: Boston City Hall Plaza Spatial Analysis (Source: modified based on Google Map)

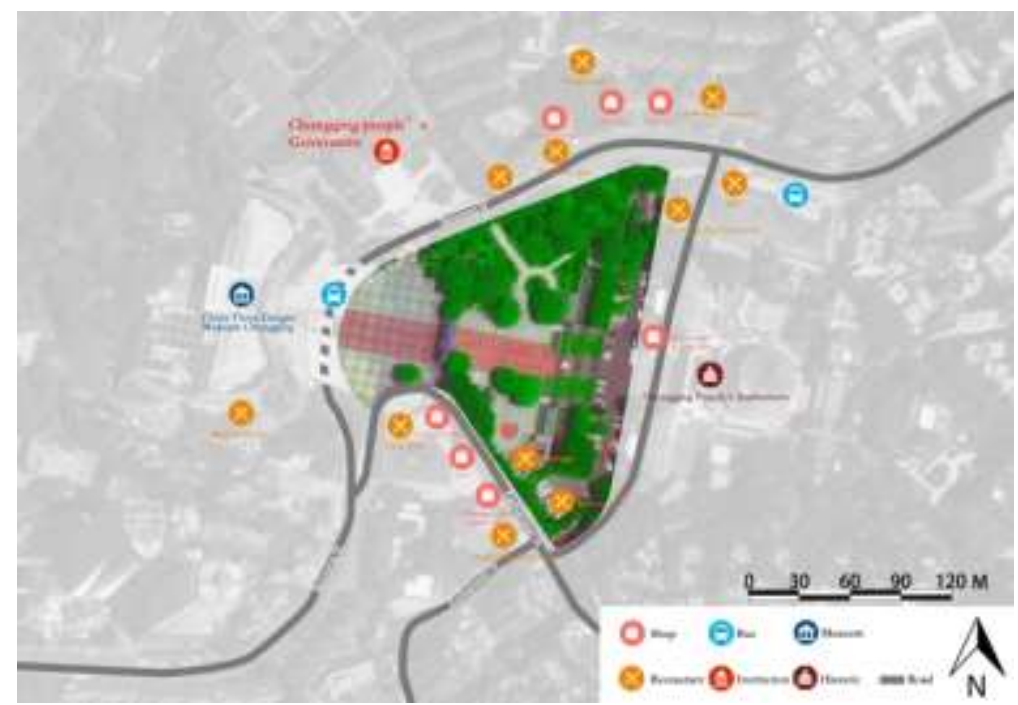

Figure 14: Chongqing People's Square Spatial Analysis

(Source: modified based on Google Map)

These two spaces are both in front of government buildings, have many restaurants and 
retailers around, and people could access each site by bus or subway. The sites have huge open plazas with some tree canopy coverage. A factor that includes an immense influence on people is using shakkei. Chongqing People's auditorium may be a traditional Chinese building style that resembles the Temple of Heaven in Beijing and is used only for events. On the other hand, Boston hall may be a controversial and distinguished example of the brutalist architecture style and work as a place for people to conduct business with various municipal agencies.

\subsubsection{Boston Faneuil Hall Marketplace Centre and Guanyinqiao Commercial Pedestrian Streets}

These two sites are both commercial areas people will walk through. People can walk into Faneuil Hall Market Place from the City Hall Plaza, and the bus station is at the west entrance. In Guanyinqiao commercial Pedestrian Street, though the subway/LRT (Light Rail Transit) entrance is within the site, therefore the majority could access it by the subway. On each site there are stores and restaurants all along the pedestrian streets and sitting space is provided beneath the tree canopy. Food stores also offer food for people along the street. However, Faneuil Hall's food court is in the middle of two parallel pedestrian streets, and Guanyinqiao business Pedestrian Streets have one single huge pedestrian street in the middle, and those mall buildings are along the road. Since Guanyinqiao commercial Pedestrian Streets was designed just around 10 years ago, the trees don't have the same canopy as Faneuil Hall's.

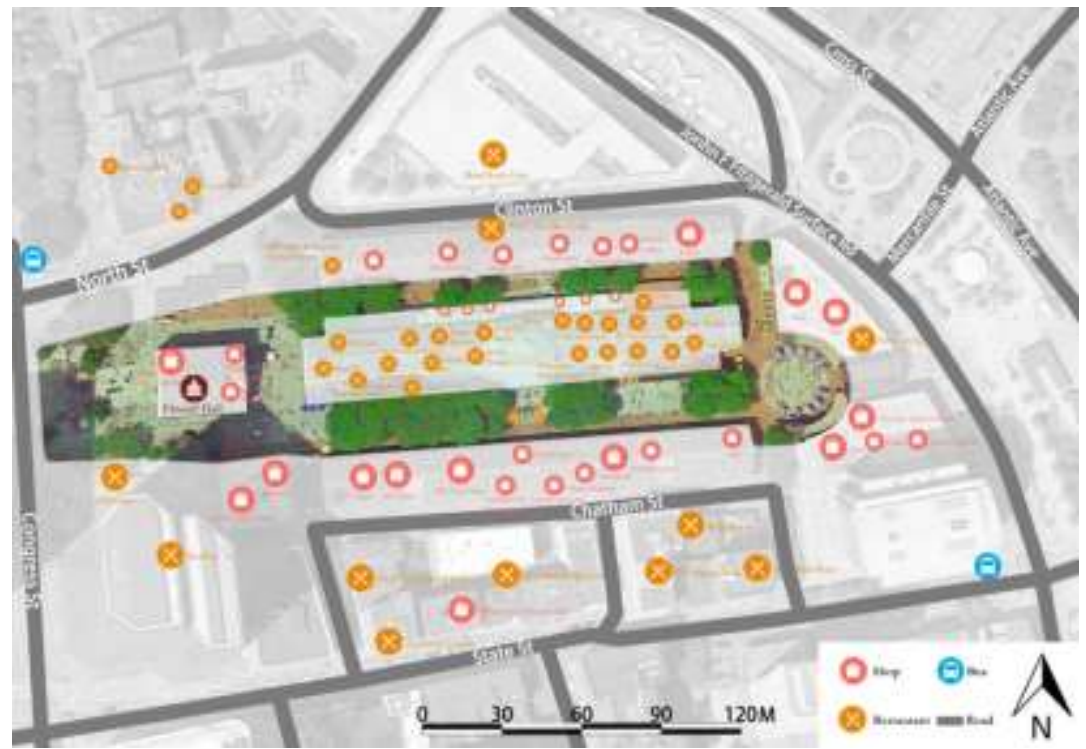

Figure 15: Boston Faneuil Hall Market Place Center Spatial Analysis

(Source: modified based on Google Map) 


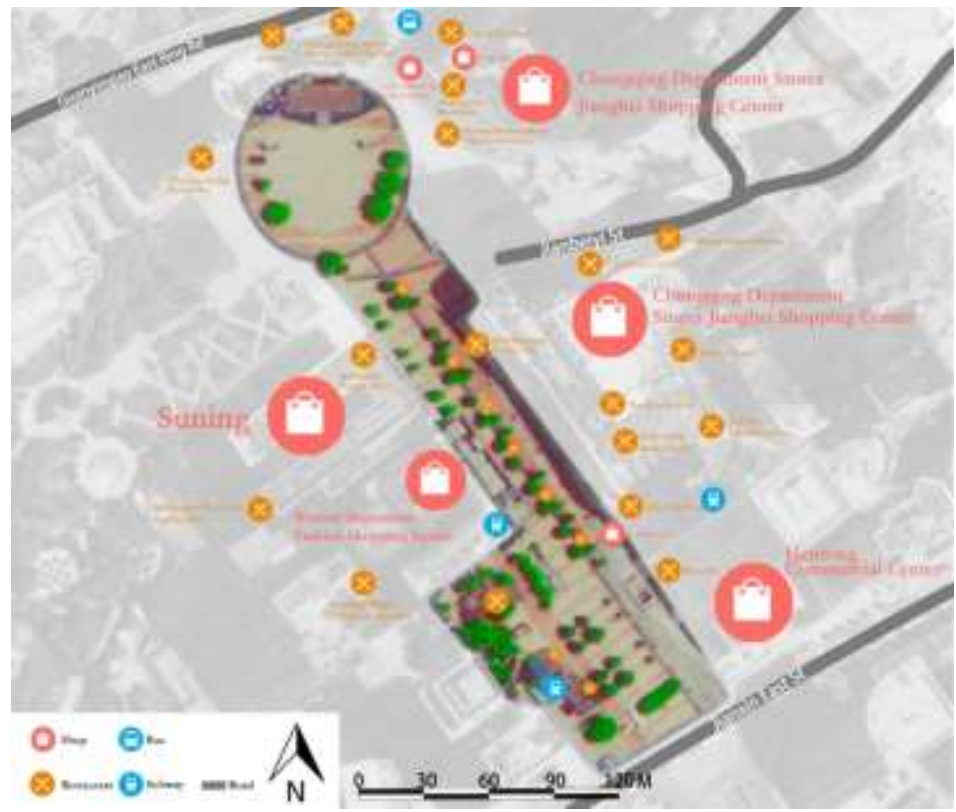

Figure 16: Chongqing Guanyinqiao Commercial Pedestrian Streets Spatial Analysis (Source: modified based on Google Map)

\subsubsection{Boston Columbus Waterfront Park and Chongqing Chaotianmen Square}

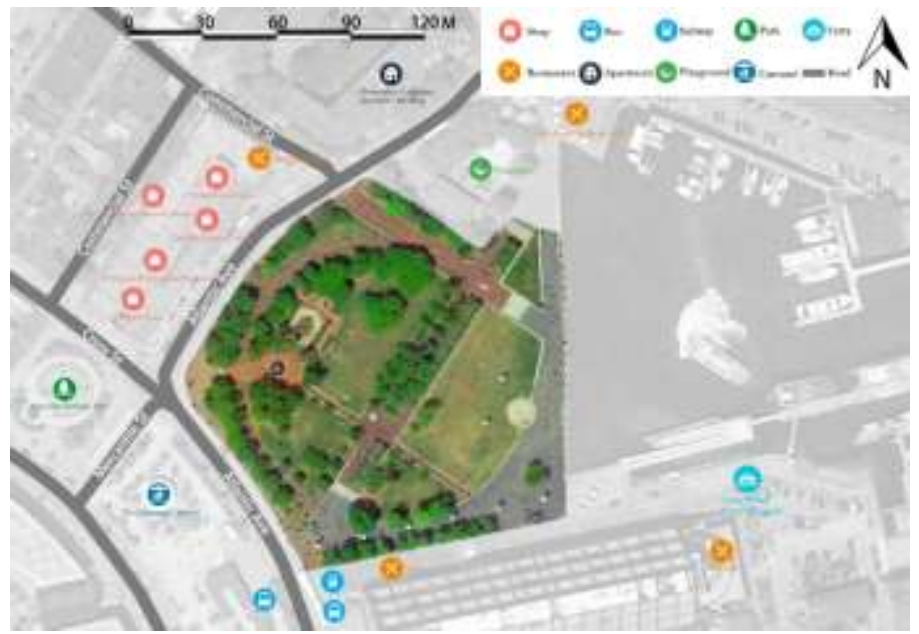

Figure 17: Columbus Waterfront Park Spatial Analysis

(Source: modified based on Google Map) 
These two sites are both near to water and each has ferry terminals near. Also, they surrounded by stores and restaurants. Many people, especially tourists within the Columbus waterfront Park come from the Faneuil Hall Market Place; the bus station is close to the entrance, and the ferry terminal in the east also bring people to the place. Most people access Chaotianmen square, however, by bus and tourist particularly foreigners from the ferry terminal in the north and not get into this site.

Another distinction is that Chaotianmen square has much more "stores," they are "popup" stalls or street vendors, thus their number is limited by the weather and the time of year. Similarly, more food vendors could appear in the morning, lunch time and dinner time. it is hard to count them because they are changing every day, however, they play a really vital part around and within the space.

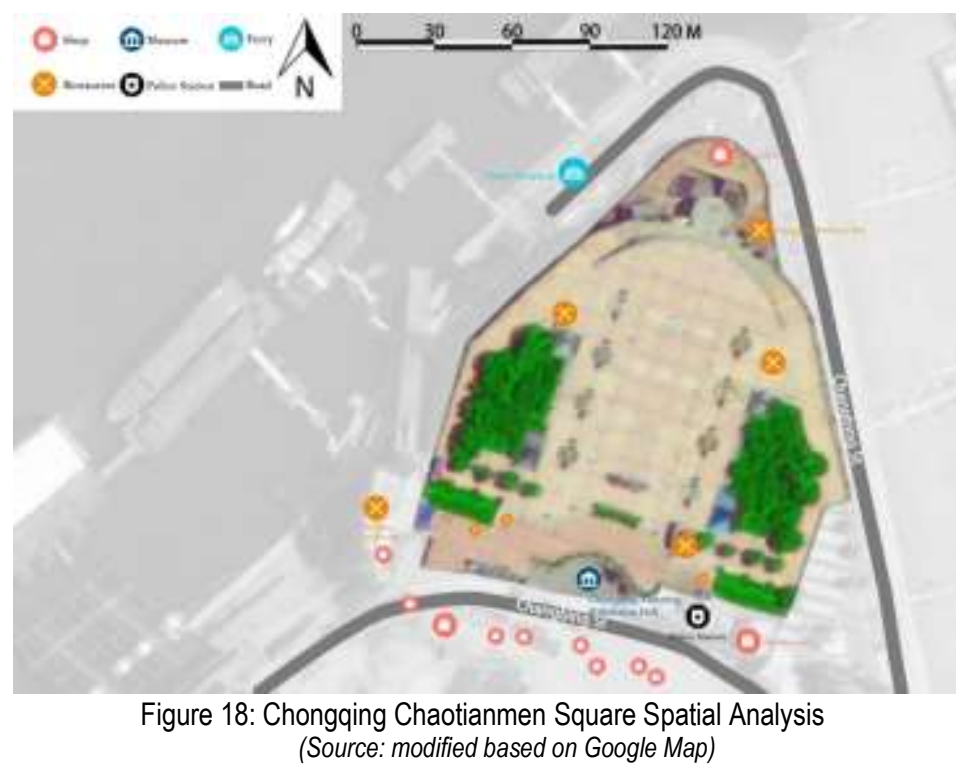

\subsection{Direct observation and site analysis}

The following direct observation is based on William Whyte's research. To achieve the research goals, the observations were conducted in a systematic way which is vital in assessing physical activity and identifying activity. the data was collected by using behavior mapping and counting; the two strategies work together at the same time.

Data are collected on three weekdays and two weekends, one Saturday and one Sunday. To get better data, the observations were conducted avoiding holidays and on days with good weather. According to William Whyte's research, one site needs a minimum of six periods of time to gather the data. Therefore in this research, they are 8:00-8:30, 10:00-10:30 12:0012:30, 15:00-15:30, 18:00-18:30 and 20:00-20:30. Many different activity types and numbers of people for every activity are represented, and every observation period has its' own time sheet. 


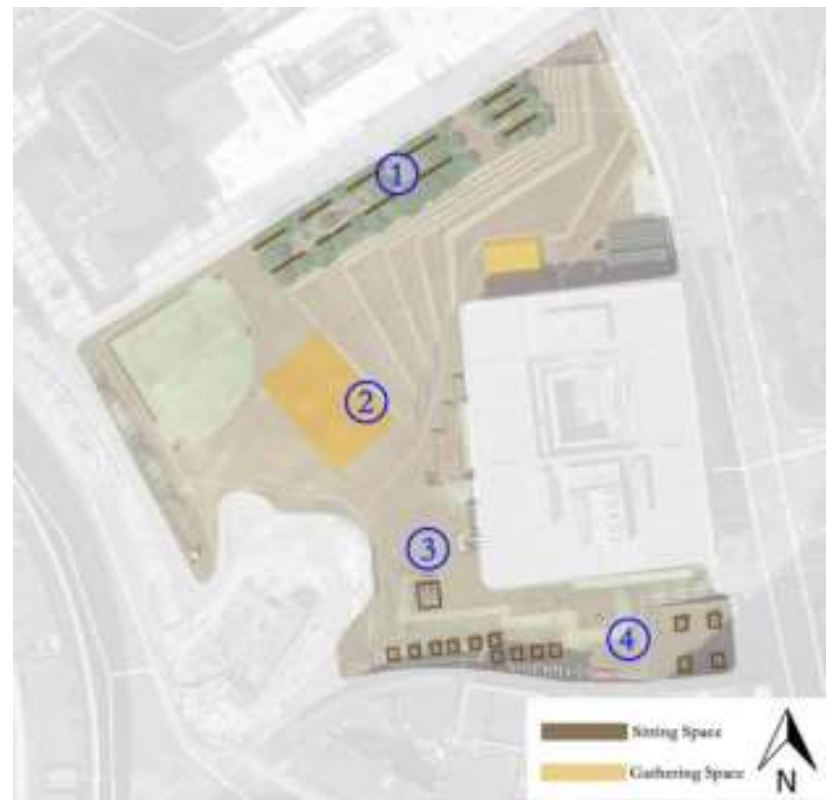

Figure 19: Boston City Hall Plaza Site Analysis

(Source: modified based on Google Map)

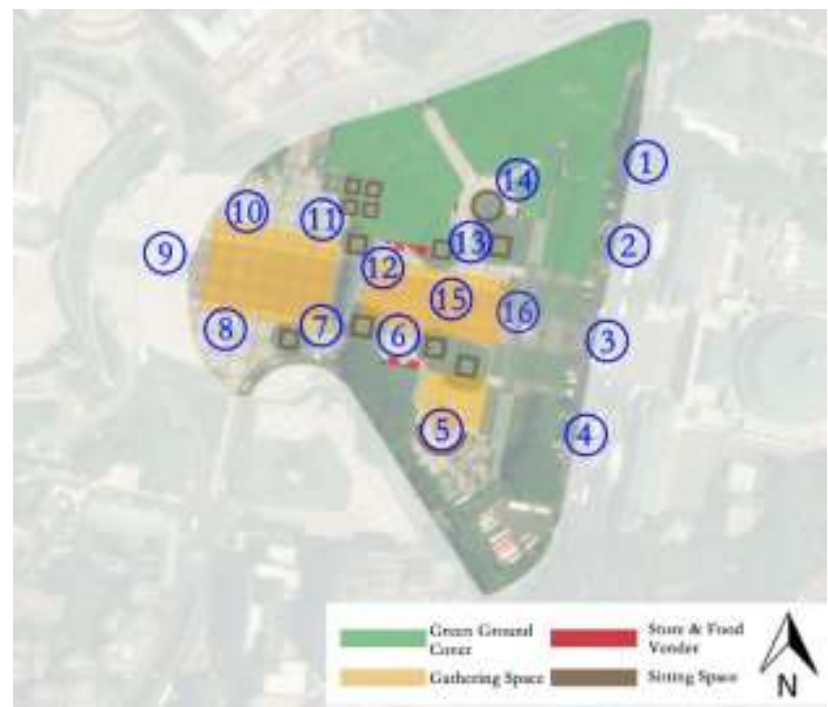

Figure 20: Boston City Hall Plaza Site Analysis

(Source: modified based on Google Map) 


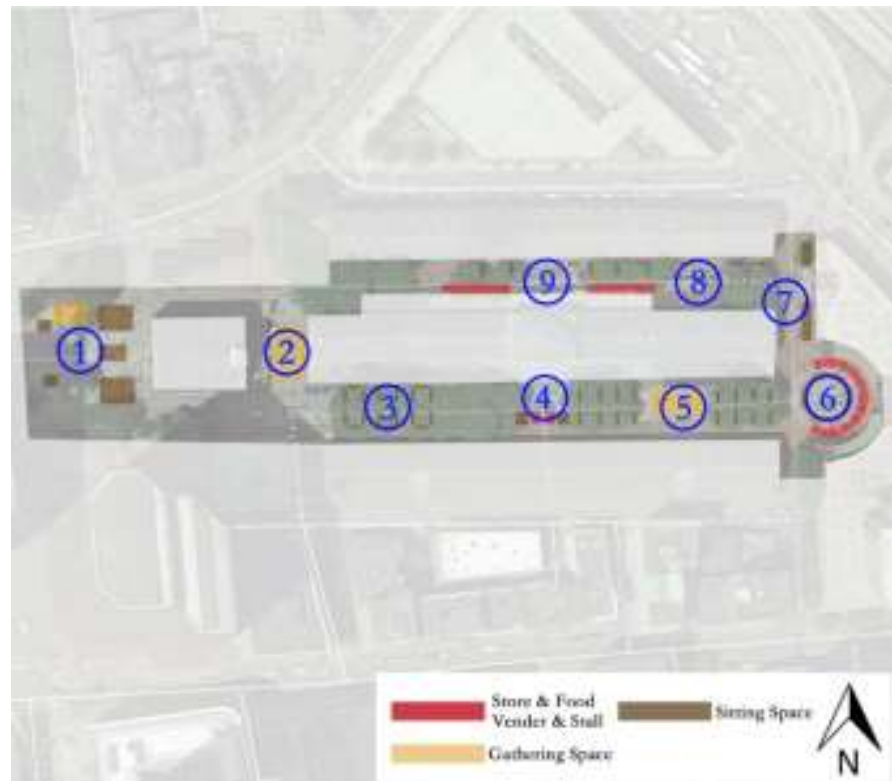

Figure 21: Boston Faneuil Hall Market Place Site Analysis

(Source: modified based on Google Map)

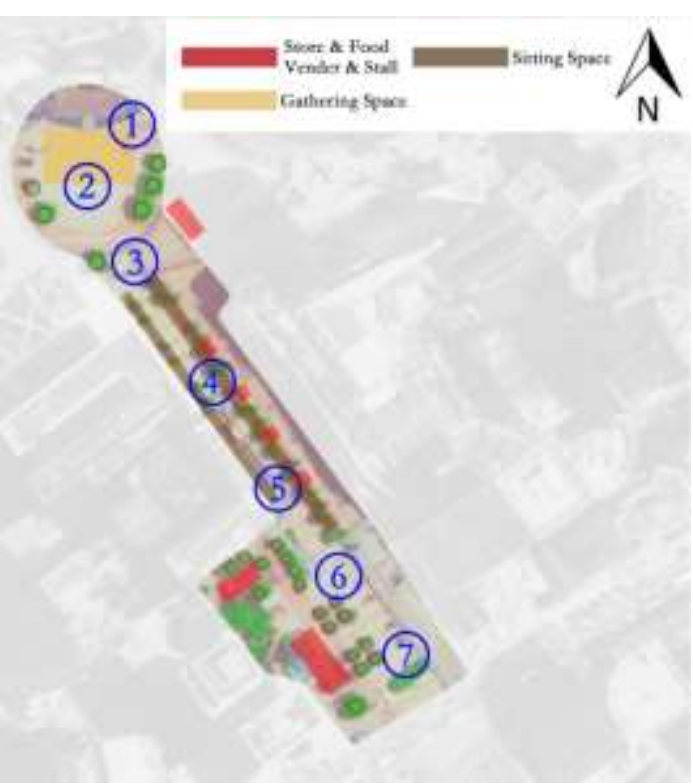

Figure 21: Guanyinqiao Commercial Pedestrian Streets Site Analysis (Source: modified based on Google Map) 
Mao, M., \& Kinoshita, I. / Asian Journal of Behavioural Studies (AjBeS), 4(15) Jan / Apr 2019 (p.51-75)

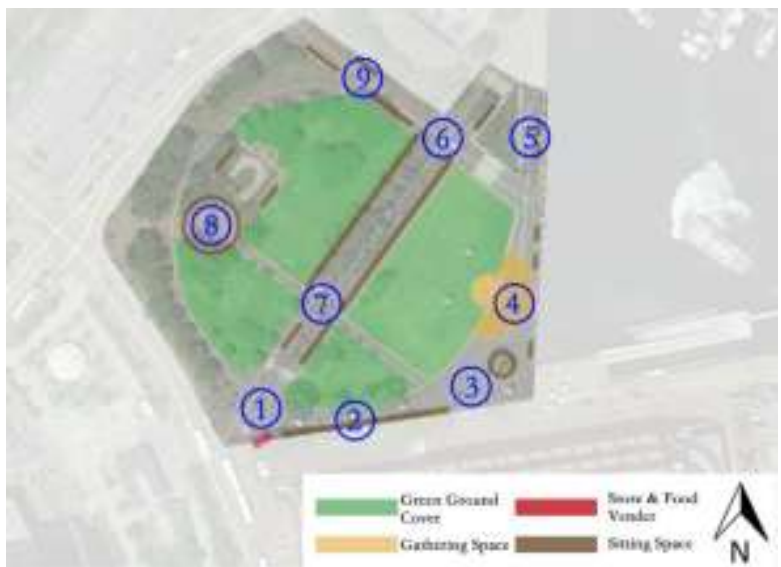

Figure 21: Boston Columbus Waterfront Park Site Analysis

(Source: modified based on Google Map)

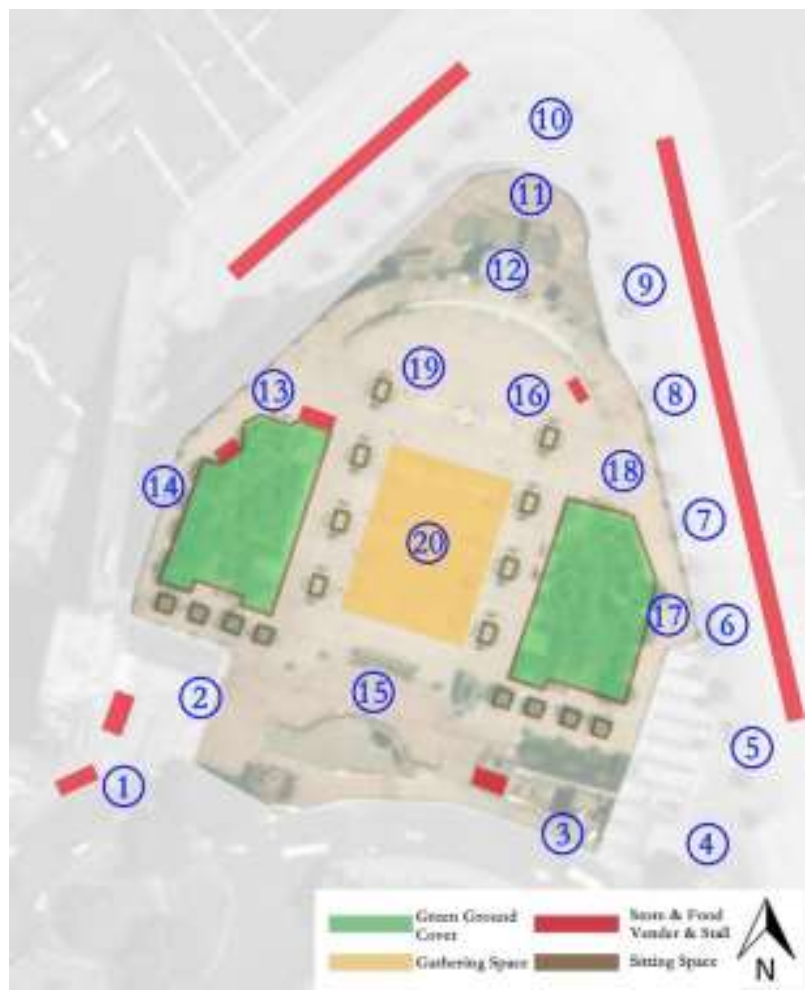

Figure 22: Chongqing Chaotianmen Square Site Analysis

(Source: modified based on Google Map) 
Every site has observation points for data collection (see appendix). This helps the observer to find the data not only in time flow but also spatially. Since the date of birth is a personal question and difficult to ask. The age information in this research is collected by the speculation of people's appearance. Since China has much more people and a higher density of population within the city, there are additional observation points in China's sites. The category of activates in the form is based on people's behavior preference and completely different from site to site; this makes the collected data much more reliable and appropriate.

\subsection{Results}

The data results in this part are analyzed with the context of Chongqing and Boston. Since China has a much bigger population and density in an urban area compared to Boston, in each site the number of people is compared in percentage and accounts for the total number of people over five days. All the data work together with spatial analysis and neighborhood analysis.

\subsection{Boston City Hall Plaza and Chongqing People's Square}

According to William H. Whyte's seven elements, trees are the main factor that affects where people stay. From the spatial analysis, point 1 in city hall Plaza is a place lined with tree cover with stone benches. This place, however, has fewer people compared to the other 3 points within the plaza. While in Chongqing People's square, point No.13 and No.14 are close to trees, and people preferred to remain and conduct other activities beneath the tree cover. All the events held in Boston city hall Plaza are scheduled by the government or another kind of organization. Point 2 in City Hall Plaza is the place to carry all types of events, people will only gather there, once there is an event. However, this place does not have many events, sometimes there are no people in that space. On the other hand, people in Chongqing People's square hold their events every day such as sword dance or Taichi in the morning and group dance when sunset.

The public plaza is a good place to do exercise and socialize with others. Nearly half of the people in Chongqing People's square are over 50, most of them are retired, so that they have more time to enjoy their life. And senior people care more about their health and have so many sorts of exercise in China, many of that are outdoor activities. This might be a cultural difference as you'll hardly ever see anyone sword dance in American public plaza. This shows people use public spaces very differently between the United States and China. Food supply could be a key factor in William H. Whyte's seven elements. There are 3 stores that sell food and drinks in Chongqing People's square, with stores that also sell all kinds of toys for kids. While there is no store in Boston city hall Plaza, the nearest restaurants are in the west. There are some tree canopies within the Boston City Hall Plaza, however, the planting beds there are too high for people to take a seat on.

\subsection{Boston Faneuil Hall Marketplace and Guanyinqiao Commercial Pedestrian Streets}

Commercial areas hold events to attract people to come so that people can shop in their 
stores. In Guanyinqiao Commercial Pedestrian Streets, people could organize and hold events by themselves. Faneuil Hall Marketplace provides space, moveable chairs, and tables, for people. Guanyinqiao Commercial Pedestrian Streets also have open areas for people, however, there are no moveable tables and chairs. Unfortunately, moveable chairs and tables might be stolen by people particularly if they are made of iron or steel. As such, those who use the open space to play Chinese chess can bring their plastic chairs and use the planting beds as tables. Therefore people in Guanyinqiao Commercial Pedestrian Streets could create their sitting space by using their plastic chairs. Guanyinqiao Commercial Pedestrian Streets have only been open for around 10 years, while Faneuil Hall Marketplace is a historical site. Trees in Faneuil Hall Marketplace are tall and provide large shadows which may cover the whole street. On the other hand, trees in Guanyinqiao Commercial Pedestrian Streets are small, and their branches cannot cover the street.

Table 1. Number of people and percentage at research sites' each observation point

\begin{tabular}{|c|c|c|c|c|c|c|}
\hline $\begin{array}{l}\text { Observation } \\
\text { points No. }\end{array}$ & $\begin{array}{c}\text { Boston City } \\
\text { Hall }\end{array}$ & $\begin{array}{l}\text { Chongqing } \\
\text { People's } \\
\text { Square }\end{array}$ & $\begin{array}{c}\text { Boston } \\
\text { Faneuil Hall } \\
\text { Marketplace } \\
\text { Centre }\end{array}$ & $\begin{array}{c}\text { Guanyinqiao } \\
\text { Commercial } \\
\text { Pedestrian } \\
\text { Streets }\end{array}$ & $\begin{array}{c}\text { Columbus } \\
\text { Waterfront } \\
\text { Park }\end{array}$ & $\begin{array}{c}\text { Chongqing } \\
\text { Chaotianmen } \\
\text { Square }\end{array}$ \\
\hline 1 & $303(19.19 \%)$ & $1262(6.81 \%)$ & $2920(25.27 \%)$ & $2806(14.82 \%)$ & $288(14.40 \%)$ & $1698(8.29 \%)$ \\
\hline 2 & $344(21.79 \%)$ & $723(3.90 \%)$ & $2332(20.18 \%)$ & $3255(17.19 \%)$ & $147(7.35 \%)$ & $1183(9.20 \%)$ \\
\hline 3 & $443(28.06 \%)$ & $975(5.26 \%)$ & $754(6.25 \%)$ & $2584(13.65 \%)$ & $355(17.75 \%)$ & $2234(1091 \%)$ \\
\hline 4 & $489(30.97 \%)$ & $442(2.38 \%)$ & $807(6.98 \%)$ & $2499(13.20 \%)$ & $266(13.30)$ & $776(3.79 \%)$ \\
\hline 5 & & $1856(10.01 \%)$ & $1185(10.25 \%)$ & $3003(15.86 \%)$ & $179(8.95 \%)$ & $1131(5.52 \%)$ \\
\hline 6 & & $1360(7.33 \%)$ & $1450(12.55 \%)$ & $2450(12.94 \%)$ & $281(14.05 \%)$ & $1417(6.92 \%)$ \\
\hline 7 & & $1011(5.45 \%)$ & $881(7.62 \%)$ & $2333(12.32 \%)$ & $224(11.20 \%)$ & $1978(9.66 \%)$ \\
\hline 8 & & $759(4.09 \%)$ & $545(4.72 \%)$ & & $167(8.35 \%)$ & $1904(9.30 \%)$ \\
\hline 9 & & $1408(7.59 \%)$ & $682(5.90 \%)$ & & $93(4.65 \%)$ & $1825(8.91 \%)$ \\
\hline 10 & & $739(3.99 \%)$ & & & & $1766(8.63 \%)$ \\
\hline 11 & & $1103(5.95 \%)$ & & & & $690(3.37 \%)$ \\
\hline 12 & & $1073(5.79 \%)$ & & & & $288(1.41 \%)$ \\
\hline 13 & & $1398(7.54 \%)$ & & & & $478(2.33 \%)$ \\
\hline 14 & & $1309(7.06 \%)$ & & & & $364(1.78 \%)$ \\
\hline 15 & & $1534(8.23 \%)$ & & & & $408(1.99 \%)$ \\
\hline 16 & & $1591(8.58 \%)$ & & & & $327(1.60 \%)$ \\
\hline 17 & & & & & & $290(1.42 \%)$ \\
\hline 18 & & & & & & $271(1.32 \%)$ \\
\hline 19 & & & & & & $391(1.91 \%)$ \\
\hline 20 & & & & & & $355(1.73 \%)$ \\
\hline
\end{tabular}

Table 2. Age distribution in each site

\begin{tabular}{ccccccc}
\hline Age & $\begin{array}{c}\text { Boston City } \\
\text { Hall }\end{array}$ & $\begin{array}{c}\text { Chongqing } \\
\text { People's } \\
\text { Square }\end{array}$ & $\begin{array}{c}\text { Boston } \\
\text { Faneuil Hall } \\
\text { Marketplace } \\
\text { Center }\end{array}$ & $\begin{array}{c}\text { Guanyinqiao } \\
\text { Commercial } \\
\text { Pedestrian } \\
\text { Streets }\end{array}$ & $\begin{array}{c}\text { Columbus } \\
\text { Waterfront } \\
\text { Park }\end{array}$ & $\begin{array}{c}\text { Chongqing } \\
\text { Chaotianmen } \\
\text { Square }\end{array}$ \\
\hline $0-6$ & $62(4.26 \%)$ & $1478(7.93 \%)$ & $479(4.42 \%)$ & $919(2.94 \%)$ & $113(6.03 \%)$ & $668(3.33 \%)$ \\
$7-18$ & $35(2.40 \%)$ & $679(3.64 \%)$ & $1082(10.00 \%)$ & $235(0.75 \%)$ & $117(6.25 \%)$ & $468(2.33 \%)$ \\
$18-34$ & $114(78.31 \%)$ & $3107(16.67 \%)$ & $7583(70.12 \%)$ & $12107(38.75 \%)$ & $1381(73.77 \%)$ & $6221(31.02 \%)$ \\
$35-50$ & $167(11.46 \%)$ & $4045(21.71 \%)$ & $1150(10.63 \%)$ & $8017(25.66 \%)$ & $208(11.11 \%)$ & $6461(32.21 \%)$ \\
$51-65$ & $41(2.81 \%)$ & $5925(31.79 \%)$ & $401(3.71 \%)$ & $5822(18.63 \%)$ & $40(2.14 \%)$ & $4497(22.42 \%)$ \\
over 65 & $11(0.76 \%)$ & $3402(18.25 \%)$ & $120(1.11 \%)$ & $4147(13.27 \%)$ & $13(0.69 \%)$ & $1742(8.69 \%)$ \\
\hline
\end{tabular}

\subsection{Boston Columbus Waterfront Park and Chongqing Chaotianmen Square}

These 2 sites are both near to water. The Boston Columbus Waterfront Park is next to the 
ocean, while Chongqing Chaotianmen square is in between the Yangtze River and the Jialing River. The number of shops, vendors, and stalls could be a huge difference between these two sites. There is only one store inside the Boston Columbus Waterfront Park, and it sells T-shirts, therefore people cannot get any food or beverages in the park. This makes the entrance, No. 2 and 3 that have the highest number of people on the site. In and Chongqing Chaotianmen square, performers also prefer a place near to the river; small bands and other entertainer perform their shows at the riverside. There are also many food vendors in Chongqing Chaotianmen square around point No.13. They serve noodles, ice-creams, and other food, which make point No.13 have a high number of people within the square. Another difference between these sites is their green spaces. Green areas in the United States are usually lawns that people are allowed to walk in, have sports such as Frisbee and walk their dog on. However, in China, lawns are rarely found in public open space. This leads to people take part in different activities in China versus the United States. While people prefer activities like jogging and dog walking in the United States, dancing, Kung Fu, tai chi and Chinese chess are more preferred in China.

Table 3. Number of people and percentage at research sites' each observation point

\begin{tabular}{|c|c|c|c|c|c|c|}
\hline Activities & $\begin{array}{l}\text { Boston } \\
\text { City Hall }\end{array}$ & $\begin{array}{l}\text { Chongaing } \\
\text { People's } \\
\text { Square }\end{array}$ & $\begin{array}{c}\text { Boston } \\
\text { Faneuil Hall } \\
\text { Marketplace } \\
\text { Center }\end{array}$ & $\begin{array}{c}\text { Guanyinqiao } \\
\text { Commercial } \\
\text { Pedestrian } \\
\text { Streets }\end{array}$ & $\begin{array}{c}\text { Columbus } \\
\text { Waterfront } \\
\text { Park }\end{array}$ & $\begin{array}{c}\text { Chongqing } \\
\text { Chaotianmen } \\
\text { Square }\end{array}$ \\
\hline Sitting & $\begin{array}{c}151(9.83 \% \\
)\end{array}$ & $1663(11.10 \%)$ & $2151(17.48 \%)$ & $4892(15.94 \%)$ & $381(18.70 \%)$ & $2010(9.82 \%)$ \\
\hline Walking & $\begin{array}{c}1260(82.0 \\
8 \%)\end{array}$ & $6409(42.78 \%)$ & $4998(40.61 \%)$ & $15840(51.62 \%)$ & $1135(55.71 \%)$ & $8191(40.01 \%)$ \\
\hline Eating & $2(0.13 \%)$ & $91(0.61 \%)$ & $494(4.01 \%)$ & $2221(7.23 \%)$ & $26(1.28 \%)$ & $526(2.57 \%)$ \\
\hline Dog Walking & $15(0.97 \%)$ & $318(2.12 \%)$ & $87(0.71 \%)$ & $150(0.49 \%)$ & $74(3.63 \%)$ & $157(0.77 \%)$ \\
\hline Social & $81(5.27 \%)$ & $1365(9.11 \%)$ & $614(4.99 \%)$ & $3366(10.97 \%)$ & $173(8.49 \%)$ & $2755(13.46 \%)$ \\
\hline Jogging & $7(0.46 \%)$ & $148(0.99 \%)$ & $17(0.14 \%)$ & 0 & $35(1.72 \%)$ & $70(0.34 \%)$ \\
\hline Cycling & $5(0.32 \%)$ & 0 & $9(0.07 \%)$ & 0 & $60(2.95 \%)$ & 0 \\
\hline Tourist & $16(1.04 \%)$ & 0 & $624(5.07 \%)$ & 0 & $36(1.77 \%)$ & 0 \\
\hline Event & 0 & 0 & $3312(26.91 \%)$ & 0 & $117(5.74 \%)$ & $5588(27.30 \%)$ \\
\hline Dance\&sing\&chess & 0 & $4187(2.78 \%)$ & 0 & $4124(13.44 \%)$ & 0 & $1119(5.47 \%)$ \\
\hline Taiji\&Kongfu & 0 & $801(5.34 \%)$ & 0 & $90(0.29 \%)$ & 0 & $54(0.26 \%)$ \\
\hline
\end{tabular}

\subsection{Discussion and Conclusion}

Public plazas and open spaces in the United States are designed to serve people, most of them have William $\mathrm{H}$. Whyte's seven elements and those elements also applied to China to some degree. There are many differences between China and therefore the United States that make people's activities and use of public plazas vary.

Most of the public plazas and open spaces in China were constructed in the past ten years. Those plants and vegetation inside the space provide less shelter for people since they are only planted for several years. And have less lawn area in China also means people have a different form of activities compared to the United States. Jogging and cycling are preferred in Boston while in Chongqing China, people do Tai Chi, sword dance, chinses chess. With cultural difference and unlike physical environment such as much more paved 
ground surfaces, make the physical environment in public space more suitable for activities dancing in China.

There are different kinds of events held in public spaces. Sword dance, public dance and Tai Chi in China are usually conducted in groups, and most of them dance at the same time, Events in the united states are typically shown with performers in the center with people around, and most of these events in the united states are well organized or programmed by a particular organization or authorities. On the other hand, most events such as tai chi and dance in China are self-organized. People who dance can come in groups, and the group leader can decide where to dance on the site. They carry their audio player, speaker, and power supply in several trolleys. However, more people participate in the event than who stand aside and watch. People's age distribution in the public plaza might partly explain the different events in China and the United States. There are more old people in public open space in China. Jogging and cycling are sports more suitable for youth or middle age, senior people in China attempt to preserve their health through lower impact activities like dance or tai chi. people in the united states also dance together, but they conduct these sorts of events inside buildings known as "The Third Place." The third place could be a space outside of work and home and creates the connection among people that live in a community (Jeffres, Bracken, Jian, \& Casey 2009). as such Americans have indoor spaces that operate as a 3rd place to conduct the group dance, however, China does not have many places work as third places, therefore the urban public space becomes their only choice.

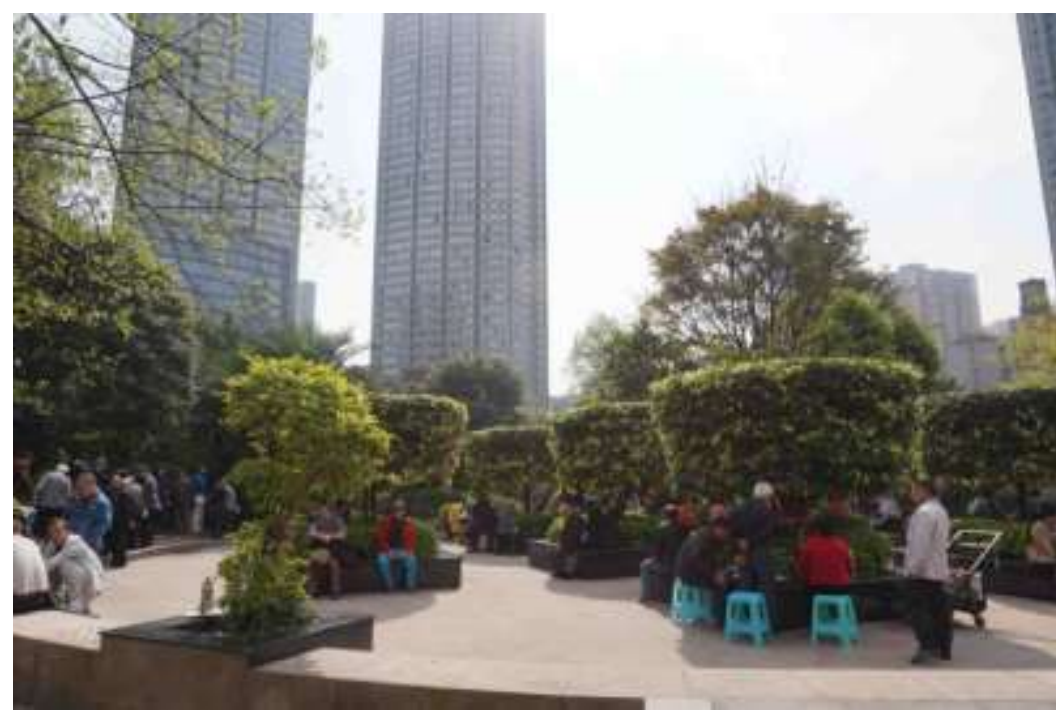

Figure 23: People bring their plastic chairs in Guanyinqiao Commercial Pedestrian

Sitting space in public space provides people an area to rest, eat and participate in different activities like chess. Moveable tables and chairs allow people to choose where to sit 
in designed sitting areas. People in China tend to make their sitting space by bringing their chairs to the site; plastic chairs and folding chairs are light in weight and simple to move around. Therefore there are more sitting spaces in China's public plazas compared to the plaza's master plan. Places beneath trees, close to green vegetation or other factors that attract people might be the potential sitting area. This sort of sitting space is located in the best place where people prefer to have their events, and those chairs only appear during the events. After the event, space is restored and serves its original purpose, which makes space become multi-usage.

Although the change in level is not one of the William $\mathrm{H}$. Whyte's seven elements, it still hugely affects people in open space. Level change in open public spaces seems to make the place less accessible for people and also cuts the connection between areas. Boston City Hall Plaza is an example in which a different level forms a different area, most people use this place as a corridor to Faneuil Hall Marketplace as the stairs keep people from the sitting space under the tree canopy. Chongqing is famous for the rugged surface, but plazas and squares are still in the same level. If Boston City Hall Plaza were in China, though, and also in a big city such as Chongqing, the situation could be different. The big open space might invite people to have their own events there after sunset. Also, the sitting space could be full of people playing Chinese chess. Its stairs could be the sitting space for people who watch the dance on that little stage. So population density, age distribution, and different culture could make a dead space in Boston become a hot spot in China.

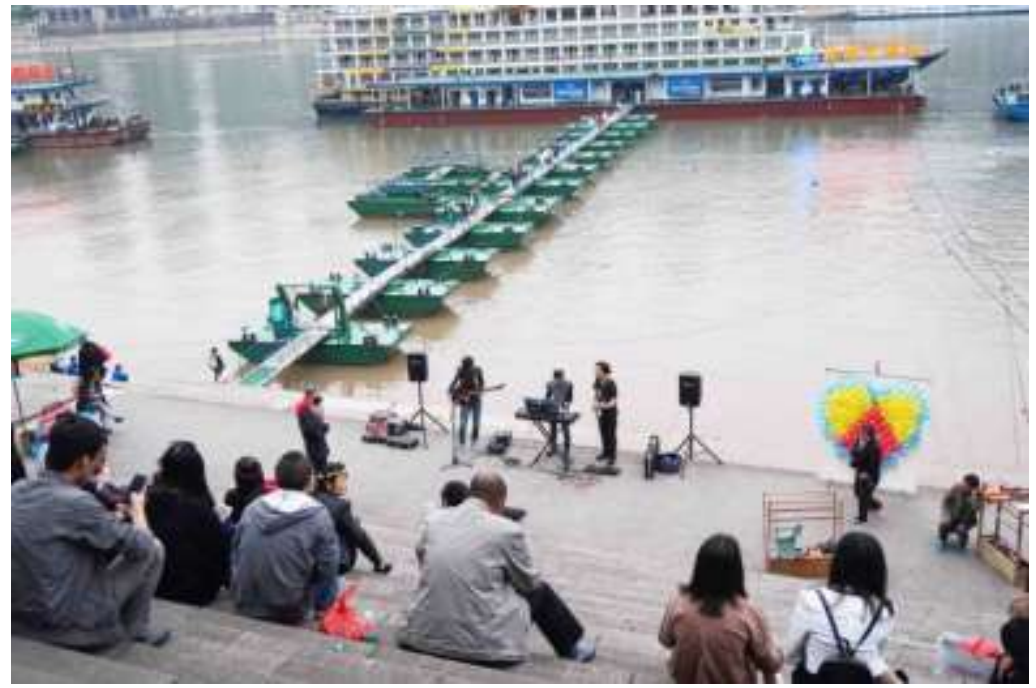

Figure 24: Example of Behaviour mapping and data collection form

Food vendors in Boston are usually well organized, and that they are always in the same place, while there are more vendors in China's open spaces such as Chaotianmen square. They are not organized, may not stay at the same site each day. There are food vendors who 
only appear during lunch time or dinner time that, and bring their chairs and tables. They are available periodically, which may become an element that draws a huge number of people. Green areas in public plazas are designed in different ways between China and the United States.

Lawns are usually open to people in United States plazas so people could picnic, rest, play disc or other sports on the grass, while lawns in China are surrounded by low shrubs two feet higher than the ground to keep people from stepping on them. The density of population might be one reason that designers in China do not want people to step on lawns. There would be much more people using the grass space if the lawns area were open to the public and it might damage the grass or make the lawn area hard to maintain.

Several elements working together could get a surprising result. Water as one of William $\mathrm{H}$. Whyte's seven elements, and attract people both in Boston and Chongqing. Water in Chongqing Chaotianmen square also works with food vendors and performers. People attracted by food and performers next to the river. The harmony of these three elements strengthens this part of Chaotianmen square and attracts way more people.

\subsection{Future Research}

This thesis explored the use of public plazas in China and the United States, where people like to stay in the plaza and how people's activities relate to the physical environment, all through the use of direct observation. There are numerous possible extensions to this research and much more research is needed.

Direct observation is one way to measure the differences, but there are other methods such as short interview and video recording. The interview could get more subjective opinion form people in public plazas. Possible interview questions could include "where would you like to rest in the plaza?" or "what kind of activities you like to do in the plaza?" The interviewer could get very detailed responses and thus make it easier for people to make any future changes to the plaza. The video recording could also provide a way to get a better understanding of how people's activities change with time.

Technology is changing our daily life, especially in developing countries such as China. Streets and open space are renewed and redesigned several times within one or two decades. One significant change is public free Wi-Fi is that is provided around bus stops and in some area of public space. Young people now bring their smartphone everywhere and they always want to be connected to the internet. A seating area with a Wi-Fi transmitter stand could attract a huge number of young people, and turn an open space into a favorite gathering spot.

This thesis has three pairs of sites; one pair at government centers, one pair in a commercial area, and one pair close to waterfronts. The site selection particularly emphasized the location of plazas. In the future research, emphasis could be put on other aspects such as the popularity of the site. There are more people in better designed and managed plazas, and few people would like to walk on a plaza that has level changes and too many stairs. When one compares popular plazas with less popular ones in both the United States and China, one may find the different elements that make public spaces more attractive to people in these two countries. To improve the reliability of the data, more plazas 
should be investigated.

People's activities in the public plaza are hugely affected by the local culture. For examples, in the United States, it's hard to find people sword dancing or playing chess in plazas. However, you can find a public space full of tables and benches in the center of Boston China town with people playing Chinese chess even though they've lived in the United States for decades. As such, having a better understanding of local culture would be very helpful in finding the differences in use of public plazas and factors that attract people in different countries.

The United States and China are two different countries, they have a different culture, different people, different environment and the way people design public plazas also differs. By using the direct observation method to compare three pairs of public plazas in Boston and Chongqing, the results show the difference in plazas designs, people's activities and also point out several elements that are different compared to William $\mathrm{H}$. Whyte's elements. Public places are all built for people and designed to meet people's needs, so further research and studies about public plazas and people's behavior in plazas would help people get a better understanding and help the design of public plazas in the future.

\section{References}

Cheshmehzangi, A., \& Heath, T. (2017). Effects of Temporary Markets on Spatial Inter-relations: A behavioural analysis of a public realm in the UK. Journal of ASIAN Behavioural Studies, 2(3), 41. doi:10.21834/jabs.v2i3.190

Gaubatz, P. (2008). New Public Space in Urban China. China Perspectives, 72-83.

Gehl, J., \& Svarre, B. (2013). How to Study Public Life. Island Press.

Helden, A. V. (2015). Are we listening to William Whyte? - Inside. Retrieved May 23, 2018, from http://www.bing.com/cr?IG=9C0247D84462448896A6B8E4A7C39C8F\&CID=32883BABFE5F628427283053FFA2 631E\&rd=1\&h=nuWwZwgNiOryXhLYZDtM9g5J7XJ_EpFemoJxwnR-teQ\&v=1\&r=http://enterinside.nl/wpcontent/uploads/2015/11/1415-S1-Anique-van-Helden-Report-THEORY.pdf\&p=DevEx.LB.1,5562.1

Jalaladdini, S., \& Oktay, D. (2012). Urban Public Spaces and Vitality: A Socio-Spatial Analysis in the Streets of Cypriot Towns. Procedia - Social and Behavioral Sciences, 35, 664-674. doi:10.1016/j.sbspro.2012.02.135

Jeffres, L. W., Bracken, C. C., Jian, G., \& Casey, M. F. (2009, October 13). The Impact of Third Places on Community Quality of Life. Retrieved from https://link.springer.com/article/10.1007/s11482-009-9084-8

Madden, K., \& Wiley-Schwartz, A. (2010). How to turn a place around: A handbook for creating successful public spaces. New York: Project for Public Spaces.

Maruthaveeran, S. (2016). The Perception of Social Safety in a Green Environment: A preliminary study at the Kepong Metropolitan Park. Asian Journal of Environment-Behaviour Studies, 1(1), 99. doi:10.21834/aje-bs.v1i1.171

Miao, P. (2011). Brave New City: Three Problems in Chinese Urban Public Space since the 1980s. Journal of Urban Design, 16(2), 179-207. doi:10.1080/13574809.2011.548980

Nasir, R. A., Ahmad, S. S., \& Ahmed, A. Z. (2016). The Relationship of Physical Activity and Human Comfort in Urban Park. Asian Journal of Behavioural Studies, 1(2), 36. doi:10.21834/ajbes.v1i2.31 
Mao, M., \& Kinoshita, I. / Asian Journal of Behavioural Studies (AjBeS), 4(15) Jan / Apr 2019 (p.51-75)

Omar, D., Ibrahim, F. I., \& Mohamad, N. H. (2017). Open Spaces and Human Interaction. Asian Journal of Behavioural Studies, 2(6), 47. doi:10.21834/ajbes.v2i6.36

Qiren, Z. (2013). Foundation for Chinas Economic Growth. Procedia - Social and Behavioral Sciences, 77, 20-26. doi:10.1016/j.sbspro.2013.03.058

Ramlee, M., Omar, D., Yunus, R. M., \& Samadi, Z. (2015). Revitalization of Urban Public Spaces: An Overview. Procedia - Social and Behavioral Sciences, 201, 360-367. doi:10.1016/j.sbspro.2015.08.187

Rasidi, M. H., Jamirsah, N., \& Said, I. (2012). Urban Green Space Design Affects Urban Residents' Social Interaction. Procedia - Social and Behavioral Sciences, 68, 464-480. doi:10.1016/j.sbspro.2012.12.242

Wan, B., \& Zhu, W. (2015). Preliminary Study of Urban Design Operation and the Regulation of Public Street in Lotus Market, Beijing, China. Procedia - Social and Behavioral Sciences, 184, 338-344. doi:10.1016/j.sbspro.2015.05.099

Whyte, W. H. (1980). The social life of small urban spaces. Project for Public Spaces.

Wu, W., \& Gaubatz, P. R. (2013). The Chinese city. London: Routledge, Taylor \& Francis Group.

\section{Appendix}

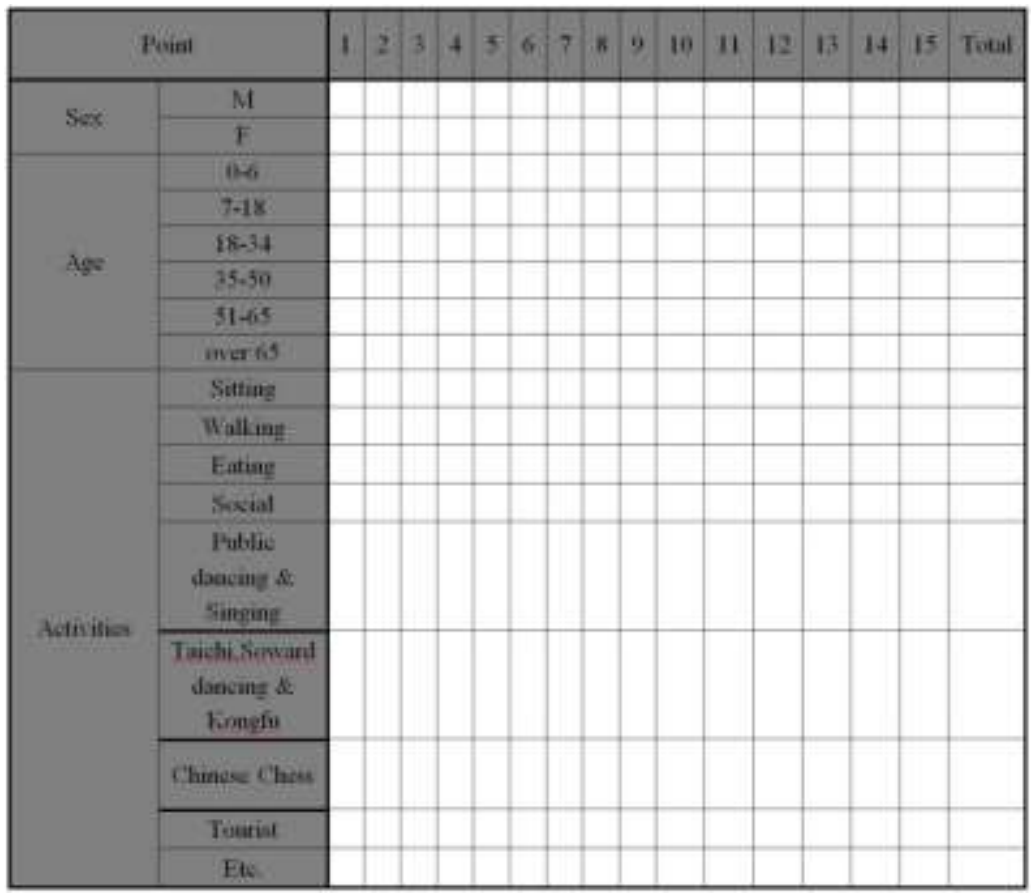

Figure 25: Example of Behaviour mapping and data collection form 